\title{
A IMAGEM \\ EM SUA \\ POTÊNCIA \\ DE CAPTURA \\ SIMBÓLICA
}

\section{L'IMAGE DANS SA PUISSANCE DE CAPTURE SYMBOLIQUE}

\author{
THE IMAGE IN ITS POWER OF SYMBOLIC CAPTURE
}

Suzy Lagazzi*

Universidade Estadual de Campinas

RESUMO: Este artigo analisa a imagem em sua potência de captura simbólica do sujeito, materializada no trajeto do olhar, a partir da afirmação de que "a imagem é uma tecnologia política de linguagem" (LAGAZZI, 2020), para compreender o funcionamento da ideologia na remissão do intradiscurso ao interdiscurso. Tendo como objeto de análise o curta-metragem Eletrodoméstica, de Kleber Mendonça Filho (2005), o percurso aqui traçado vai delineando trajetos do olhar que se ancora na busca que o corpo faz movido pelo desejo e marcado pela falta. São trajetos em que as formulações visuais vão mostrando o funcionamento equívoco desse corpo na relação com os eletrodomésticos, o tempo e o espaço da casa.

PALAVRAS-CHAVE: Imagem e discurso. Imagem e equívoco. Corpo e imagem. Análise discursiva visual. Eletrodoméstica (curtametragem).

RÉSUMÉ: Cet article analyse l'image dans sa puissance de capter symboliquement le sujet par l'itinéraire du regard à partir de l'affirmation que "l'image est une technologie politique de langage" (LAGAZZI, 2020), pour comprendre le fonctionnement de l'idéologie dans le renvoi de l'intradiscours à l'interdiscours. À partir de l'analyse du court métrage Eletrodoméstica, de Kleber Mendonça Filho (2005), le parcours décrit ici nous montre les chemins du regard qui s'ancre dans la recherche que fait le corps, mu par le désir et marqué par le manque. Ce sont des chemins où les formulations visuelles nous révèlent le fonctionnement équivoque de ce corps dans ses rapports avec les appareils électroménagers, le temps et l'espace de la maison.

MOTS CLÉS: Image et discours. Image et équivoque. Corps et image. Analyse discursive visuelle. Eletrodoméstica (court métrage).

ABSTRACT: This article analyzes the image in its power to capture the subject by the gaze in its path, from the statement "image is a political technology of language" (LAGAZZI, 2020), understanding the functioning of ideology in the remission of intradiscourse to interdiscourse. Having the short film Eletrodoméstica - by Kleber Mendonça Filho (2005) - as an object of analysis, the route traced here aims to outline paths of the gaze anchored in the search that the body performs moved by desire and marked by lack.

\footnotetext{
* Professora Colaboradora do Departamento de Linguística do Instituto de Estudos da Linguagem da Universidade Estadual de Campinas (DL/IEL/Unicamp) e integrante do Centro de Pesquisa PoEHMaS (IEL/Unicamp). E-mail: slagazzi@gmail.com.
} 
These are paths in which visual formulations show the equivocal functioning of that body in the relationship with the household appliances, time, and space of the house.

KEYWORDS: Image and discourse. Image and equivoque. Body and image. Visual discursive analysis. Eletrodoméstica (short film).

\section{RETOMADA}

Diante do tema da imagem no digital, a questão de sua circulação e sua potência de mobilizar o sujeito tomam vulto. Em meu percurso, retorna e insiste a compreensão de que "a imagem é uma tecnologia política de linguagem que afeta o sujeito" (LAGAZZI, 2020) e o demanda em seus gestos e práticas. Retomo essa afirmação de um mo(vi)mento anterior ${ }^{1}$, em que meu investimento sobre a análise de fotografias vinha me mobilizando para dar visibilidade à partição do social. Seja na fotografia, seja em vídeos, documentários e filmes, seja nas capas de livros e revistas, tomar a imagem como uma tecnologia política me impôs perguntas, que continuam a derivar para novas questões.

Nesse momento anterior, ressaltei o gesto de "olhar para o movimento dos sentidos no rastro das práticas que sustentam as tecnologias linguageiras" (LAGAZZI, 2020), dando relevo à inscrição política do sujeito no social, em meio às diferentes materialidades significantes. Na retomada que ora acontece, importa pensar a inscrição política do sujeito no social pela imagem. Como a imagem convoca o sujeito? A relação com a imagem convoca o sujeito a que práticas simbólicas? Como o possível se configura em deriva para o sujeito na relação com a imagem?

Finalizei esse movimento anterior sobre a imagem falando em sua "potência de captura simbólica" (LAGAZZI, 2020), que nos convida à interlocução no confronto dos sentidos. Buscar essa potência, analisar a imagem em suas possibilidades simbólicas, compreender o movimento de captura do sujeito pela imagem são alguns dos desafios que me movem neste artigo.

\section{DELINEANDO O TERRENO}

A compreensão da imagem como uma "tecnologia política de linguagem" vem marcar seu lugar como dispositivo ideológico, concebido a partir da perspectiva materialista à qual me filio. Justamente na consequência dessa filiação, importa dar visibilidade à "potência de captura simbólica" desse dispositivo tecnológico em circulação, analisando o funcionamento da ideologia nos processos de identificação suscitados pela imagem.

Quando Orlandi (2001, p. 11-12) chama a atenção para a circulação dos sentidos, ressaltando a importância de considerarmos, na análise, "os trajetos dos dizeres", acrescenta que "os 'meios’ nunca são neutros”. Esta afirmação funciona como um alerta para não nos esquecermos de um dos princípios fundamentais na análise do discurso materialista: os sentidos são efeitos produzidos a partir de determinações históricas, o que significa buscarmos sempre a sua desnaturalização. As perguntas são as nossas ferramentas primeiras, e fazer uso delas no que concerne à circulação da imagem no digital é um procedimento de grande consequência para que os sentidos possam ser analisados em suas condições de produção, para que possamos desconfiar das verdades que nos tomam pela desconstrução das evidências.

Silveira (2019), em sua discussão sobre discurso, arquivo e tecnologia, sintetiza bem várias das implicações da circulação do digital:

Pesquisadores de diferentes áreas do conhecimento se dedicam hoje ao estudo das implicações políticas e sociais da internet, da web, do virtual, dos aplicativos, dos gadgets, ou seja, desse complexo campo que tem se convencionado nomear por "digital". Discute-se, entre outras coisas, a circulação dos textos, a problemática dos bancos de dados, os mecanismos de vigilância, a gestão dos conteúdos. (SILVEIRA, 2019, p. 37)

\footnotetext{
${ }^{1}$ Apresentação feita no VIII Encontro de Estudos da Linguagem e VII Encontro Internacional de Estudos da Linguagem - Enelin 2019, na Universidade do Vale do Sapucaí (Univás), Pouso Alegre (MG). Vide Lagazzi (2020).
} 
Justamente as implicações políticas e sociais desse complexo campo nomeado como "digital”, tal como pontuado por Silveira (2019), discutidas na relação com a imagem, retornam em meu percurso na insistência sobre a potência da imagem em mobilizar os sujeitos.

Sem endossar o poder da imagem sobre as palavras e sobre outras materialidades significantes - normalmente resumido pelo aforisma "uma imagem vale mais que mil palavras" -, uma vez que meu investimento vai na direção de analisar a produção dos sentidos na imbricação das diferentes materialidades ${ }^{2}$, acredito que falar da captura simbólica do sujeito pela imagem e dos processos ideológicos de identificação aí envolvidos é estabelecer, pelo olhar, uma relação ímpar com a produção de sentidos. Quero insistir sobre essa potência da imagem de captura simbólica do sujeito, materializada no trajeto do olhar.

\section{RETORNO AO PONTO DE INFLEXÃO}

Alguns gestos de compreensão pedem retorno. Em meu percurso analítico pela imagem, o fotograma recortado do documentário Boca de Lixo (1993), de Eduardo Coutinho, que apresenta os catadores fletidos em meio ao lixão, guarda o gesto que foi fundador de minha compreensão sobre o modo pelo qual a memória discursiva e a formulação se entrecruzam visualmente. Gosto de dizer que esse fotograma marca um ponto de inflexão analítica. No movimento de descrevê-lo em batimento com a interpretação, a imagem foi me demandando no contraponto de seus elementos e foi fazendo sentido na relação com a memória do dizer. Esse batimento, que venho trabalhando como a remissão do intradiscurso ao interdiscurso na deslinearização da imagem (LAGAZZI, 2013, 2014), é fundamental para compreendermos o trabalho da ideologia.

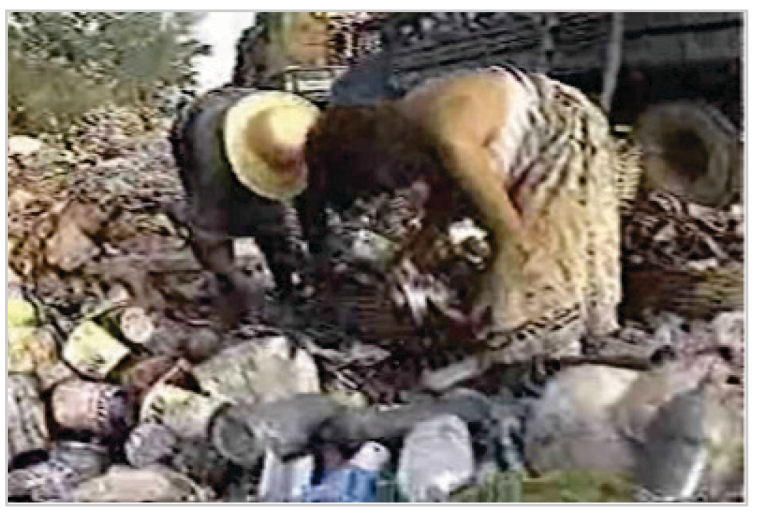

Imagem 1: Fotograma recortado de Boca de Lixo

Fonte: BOCA de lixo (1992)

Entre o familiar e o estranho, o olhar oscila entre o reconhecimento e o desconhecimento. O contorno dos corpos, que ao mesmo tempo se destacam de e se misturam com o lixo, nos confronta com a equivocidade da imagem, que nos fala da equivocidade dos sentidos. Ser catador é ter qual relação com o lixo? A posição dos corpos, que remete à memória do trabalho braçal, insiste em afirmar, no documentário, o catador como um trabalhador. Mas catar lixo é trabalhar? Essa pergunta ressoa e incomoda. Reivindicar o sentido de trabalho faz parte da luta diária do catador que nos é apresentado em Boca de Lixo.

Pêcheux (1990) analisou brilhantemente a equivocidade na relação com as palavras e os enunciados. "Quem ganhou o quê?"3. Essa pergunta, com a qual o autor nos mostra a importância do jogo parafrástico como procedimento analítico discursivo, é o ponto de sustentação de toda a discussão empreendida para dar consequência à sua posição materialista na relação com a interpretação.

\footnotetext{
${ }^{2}$ Sobre a imbricação das diferentes materialidades significantes, vide Lagazzi $(2009,2015,2017)$.

${ }^{3}$ A análise de Pêcheux (1990) incide sobre o enunciado "on a gagné", ressaltando a importância da retomada dos complementos possíveis para o pronome "on" e para o verbo "gagné".
} 
Assumindo seu dispositivo de leitura também para a imagem, volto a parafrasear Pêcheux (1990, p. 53): “[...] toda descrição está intrinsicamente exposta ao equívoco da [imagem ${ }^{4}$ ]: [toda imagem] é intrinsecamente suscetível de tornar-se outra, diferente de si mesma, se deslocar discursivamente de seu sentido para derivar para um outro [...]".

Descrever a imagem em paráfrases visuais, eis a proposta.

Localizar o equívoco na formulação do fotograma recortado de Boca de Lixo é trabalhar no entrecruzamento da formulação visual e da memória discursiva. O que faz estranhar nesse fotograma? O que incomoda? A quem incomoda?

O corpo fletido do catador em meio ao lixo faz ressoar a memória do trabalho braçal, o que não significa que essas imagens sejam significadas, sem hesitação, como corpos em trabalho. O lixo incomoda. Um corpo em meio ao lixo incomoda. O lixo e o corpo não fazem parte da mesma família parafrástica segundo os padrões de higiene e saúde legitimados, por exemplo, pela Organização Mundial da Saúde (OMS). Há uma divisão dos sentidos que recusa a associação corpo e lixo e, portanto, recusa o lixo como possibilidade de trabalho. É sintomático ouvir os catadores, em Boca de Lixo, afirmando estarem trabalhando e não roubando ou matando. Essa reivindicação pela legitimação do sentido de trabalho para o gesto de catar lixo é uma regularidade no documentário e marca uma posição-sujeito contrária àquela que recusa a relação entre corpo, lixo e trabalho. Duas posições ideologicamente distintas, que naturalizam distintas relações de sentido. E a equivocidade vem nos mostrar que o trabalho da ideologia vai recortando a interpretação e estabilizando diferentes versões ${ }^{5}$. Um mesmo fotograma permitindo e negando, em simultâneo, a interpretação do catador como trabalhador. A contradição sustentando a produção dos sentidos e as diferentes condições de produção organizando sua divisão.

Trabalhando a contradição na relação com a imagem, dei consequência à remissão do intradiscurso ao interdiscurso. A imagem se abre para a interpretação a partir das determinações históricas em que as formulações visuais se produzem e circulam. A memória discursiva intervém sobre a formulação visual nesse jogo de remissão do intra ao interdiscurso.

A cena dos catadores fletidos em meio ao lixo, que se apresenta como uma composição equívoca, traz formulações visuais em contradição. O entorno do lixo parece, à distância, não ter fim. Um não acabar de dejetos indistintos, vasilhames vazios, jogados, amassados, que, na versão legitimada por nossa sociedade, não deveriam compor uma mesma cena com corpos humanos, não deveriam estar sendo manuseados, o lixo não deveria estar sendo vasculhado. Essa composição produz resistência ao nosso olhar legitimador. Na memória discursiva socialmente estabilizada, as imagens que remetem aos sentidos de lixo não fazem laço com as imagens de corpos e tampouco com a memória de corpos em trabalho. Há um olhar que estranha essa composição que incomoda uma grande parcela desta nossa sociedade, para quem o lixo, como trabalho, não se configura em memória visual discursiva. Há um hiato visual em termos da memória discursiva que separa lixo, corpo e trabalho. A ideologia delimita o território dos sentidos e determina o trajeto do olhar.

\section{O OLHAR EM CENA}

Compreender o funcionamento da ideologia na relação com a imagem pelo trajeto do olhar, no fotograma recortado de Boca de Lixo, me levou a um percurso socialmente sensível pelos sentidos de trabalho e de corpo.

Dentro dessa temática que relaciona trabalho e corpo, um outro percurso analítico tem me demandado na direção de pensar o olhar em sua prática ideológica. Trata-se da análise do curta-metragem Eletrodoméstica, de Kleber Mendonça Filho (2005).

\footnotetext{
${ }^{4}$ Em artigo anterior (LAGAZZI, 2015, p. 184)), substituo os termos 'língua' e 'enunciado', usados por Pêcheux (1990), por “materialidade significante" e

"formulação". Nesta nova paráfrase trago "imagem" para as duas substituições.

${ }^{5}$ Orlandi (2001, p. 17) afirma que, "pela textualidade, a possibilidade mesma da formulação em suas diferentes materialidades, abre-se para as versões possíveis".
} 
O filme nos apresenta o cotidiano de uma dona de casa, residente do bairro de Setúbal, em Recife, cujo dia a dia se estrutura por sua relação com os eletrodomésticos que integram sua casa e sua vida. Vemos um apartamento completamente cercado por grades que enclausuram a família em seu interior. A máquina de lavar roupas, o relógio digital, a televisão, o forno micro-ondas, o telefone sem fio, o aspirador de pó, o ventilador, o computador, a faca elétrica compõem o cenário e protagonizam, juntamente com a dona de casa, a narrativa tecida. O desejo costura as cenas num jogo equívoco entre tempo, corpo, trabalho e prazer, em que os sentidos transitam questionando muitas evidências.

Perder o olhar por entre as grades, abrir e fechar cadeados, portas e portões na insistência da segurança ilusória. Essas cenas vão se encadeando no filme e constroem uma regularidade.
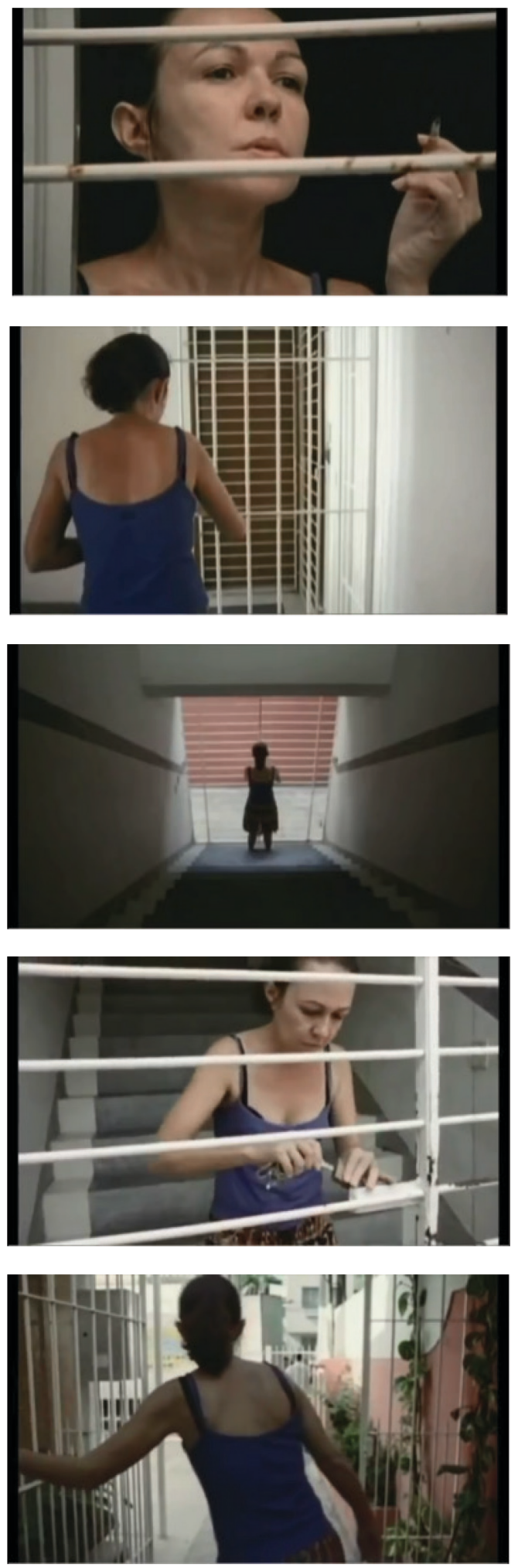


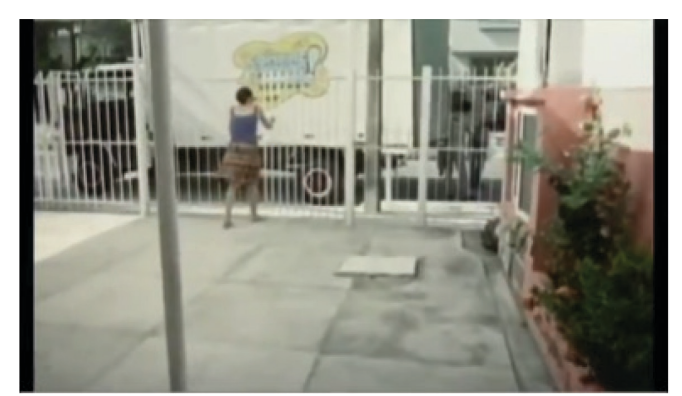

Imagem 2: Eletrodoméstica

Fonte: ELETRODOMÉSTICA (2005)

O mundo protagonizado em Eletrodoméstica é um mundo barrado. O olhar, que no primeiro fotograma dessa série se lança grade afora, é uma das possibilidades de escape de um corpo controlado espacial e temporalmente. Esse olhar da protagonista, que escapa ao olhar do espectador, marca um trajeto de busca, em que a falta se faz constitutiva.

A falta, na relação com a cadeia significante, vem marcar, pela metonímia, "o desejo, desejo de outra coisa que falta sempre" (DUCROT; TODOROV, 1982, p. 416). E essa sempre falta que constitui a cadeia significante é a brecha possível de irrupção de um outro significante vindo de uma outra cadeia, irrupção que vai caracterizar a metáfora. No cruzamento desses dois processos, metáfora (condensação que marca o recalque) e metonímia (deslocamento ocasionado pela falta), a linguagem se produz sempre na incompletude, na provisoriedade do movimento dos sentidos e da busca para tentar tamponar o desejo.

Em Eletrodoméstica, o desejo atravessa a relação entre trabalho e corpo na busca do sujeito pelo prazer. O relógio de pulso e cronômetro digital é o instrumento que organiza, pelo olhar, a relação entre trabalho e corpo. O tempo do ciclo da máquina de lavar roupas determina a duração da sequência das tarefas a serem executadas.
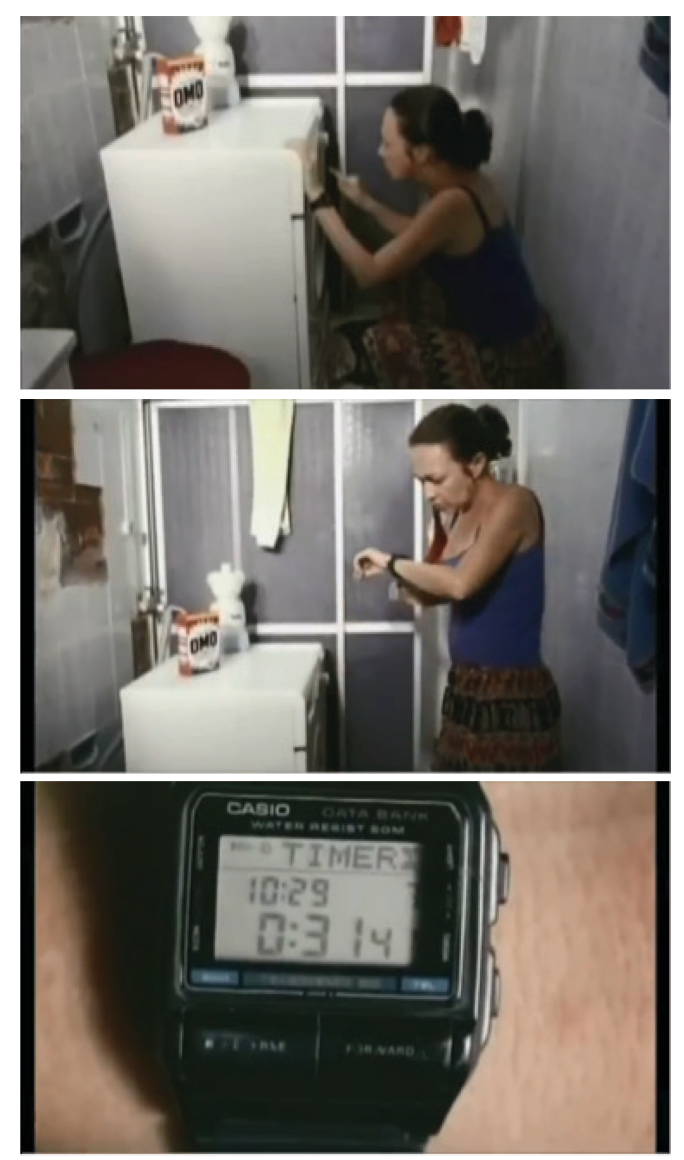

Imagem 3: Eletrodoméstica 
Em contraponto ao olhar que escapa pela janela em busca do que sempre falta, temos aqui o olhar da dona-de-casa, que foca o cronômetro e traz ao seu encontro o olhar do espectador. A tela coloca em primeiro plano os minutos e segundos a serem cronometrados. O início do ciclo marca o início da contagem regressiva.

Cronômetro acionado, hora de a protagonista dar sequência à sua rotina doméstica. Entra em cena o aspirador, trazendo uma inusitada interlocução com o corpo da dona de casa:
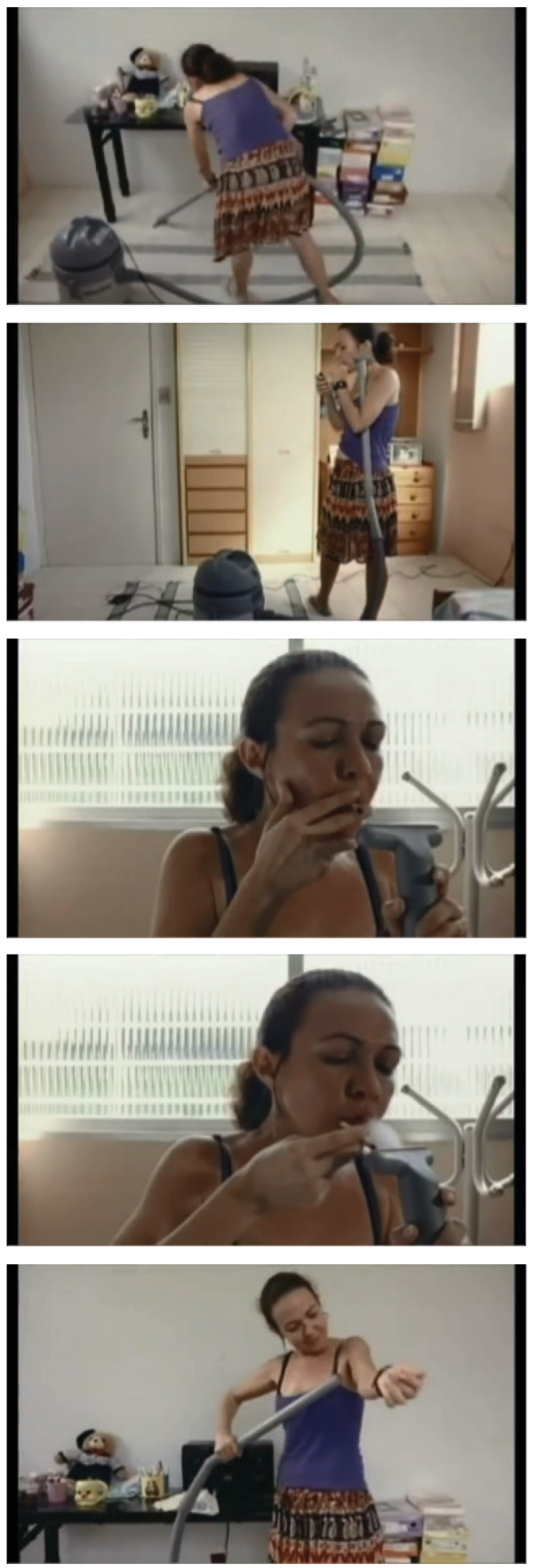

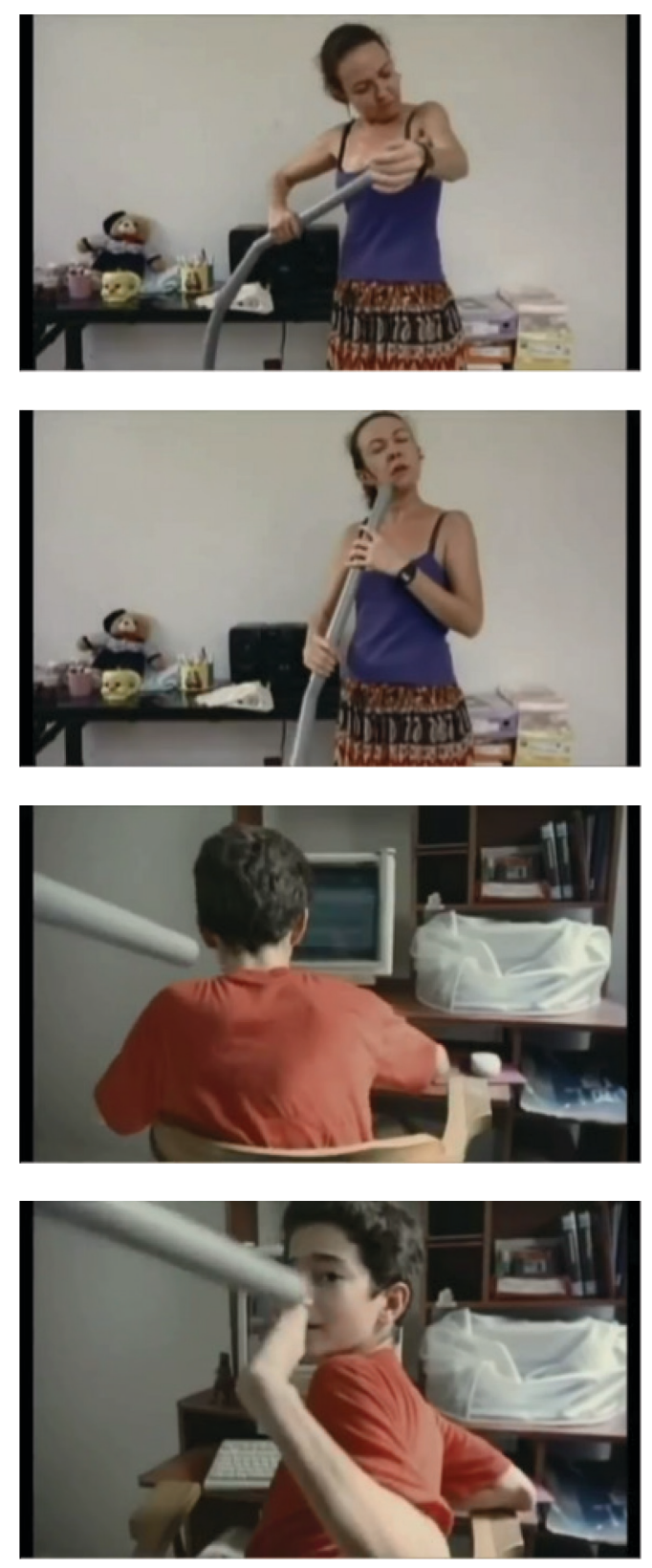

Imagem 4: Eletrodoméstica

Fonte: ELETRODOMÉSTICA (2005)

Se, no primeiro fotograma desta série, a posição do corpo fletido é a que evoca a memória do trabalho braçal, nos fotogramas seguintes, a posição do corpo fica totalmente liberada dessa memória. As formulações visuais em cena dão ênfase a uma relação de interlocução entre o aspirador e o corpo em que o sentido de trabalho dá lugar à ludicidade e ao prazer. O corpo brinca e se diverte com o aspirador. As imagens deslocam o sentido de utilidade. Pra que serve um aspirador de pó? O olhar do espectador se desorganiza diante do imprevisto das formulações visuais e as imagens se abrem para a polissemia. A pergunta insiste: Pra que serve um aspirador de pó? Para aspirar a fumaça do baseado, sugar a pele, brincar com o filho e aspirar o pó.

O equívoco movimenta a relação entre a dona de casa, seu olhar, seu corpo, seu tempo, seu prazer, o espaço da casa, o trabalho doméstico e os eletrodomésticos. 

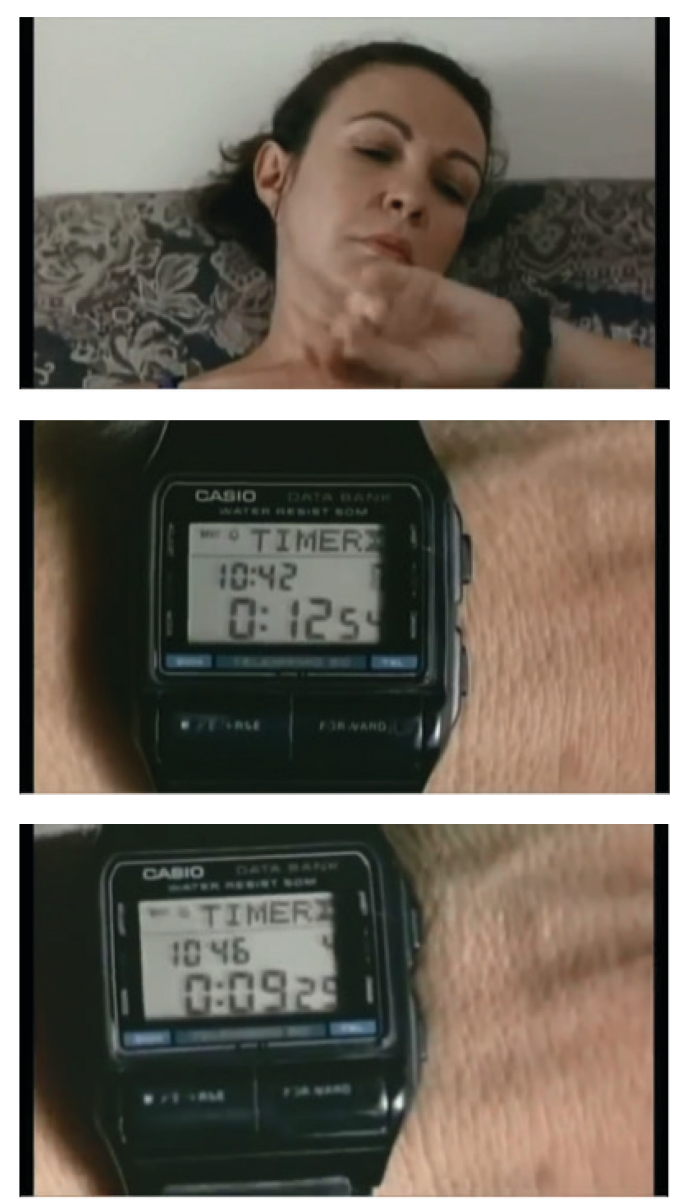

Imagem 5: Eletrodoméstica

Fonte: ELETRODOMÉSTICA (2005)

Novamente o olhar do espectador é capturado no foco da contagem regressiva. O relógio de pulso e cronômetro digital controla o tempo do ciclo da máquina de lavar, controlando a dona de casa que se mede nesse tempo. O cronômetro vai exibindo os minutos e segundos que ainda restam para a finalização do ciclo.
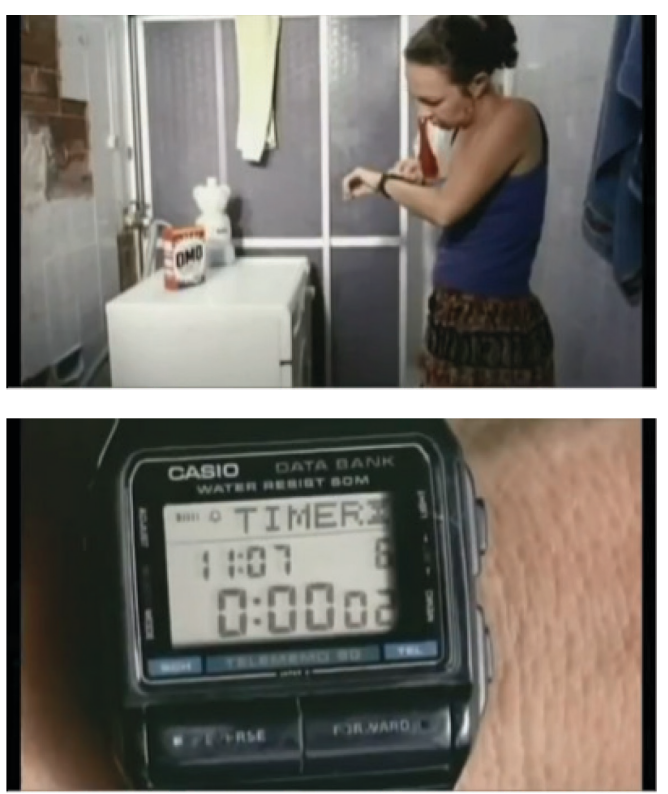

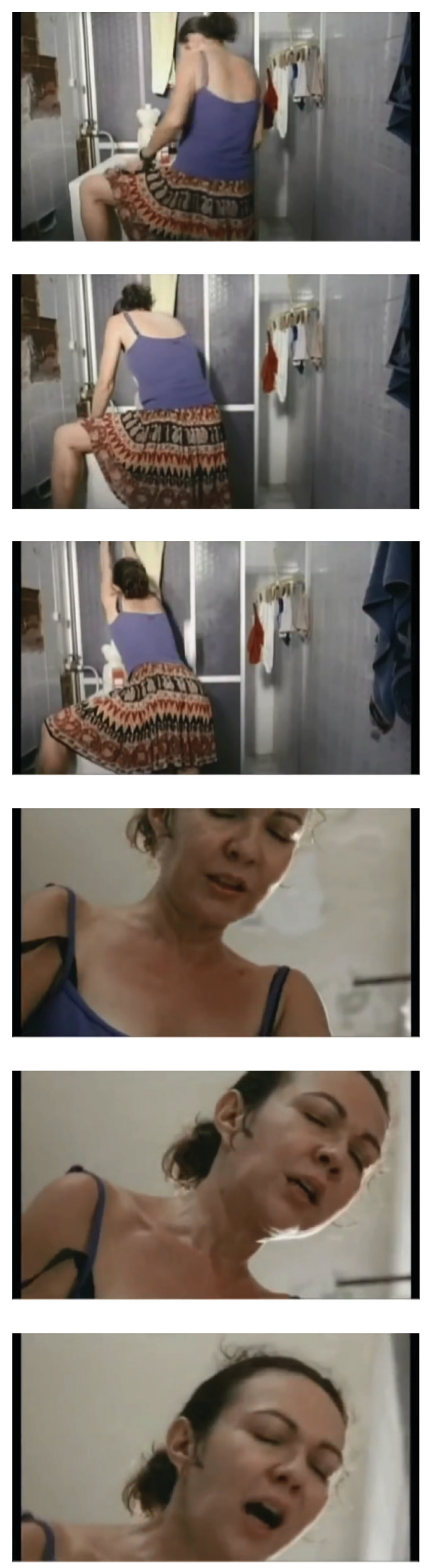

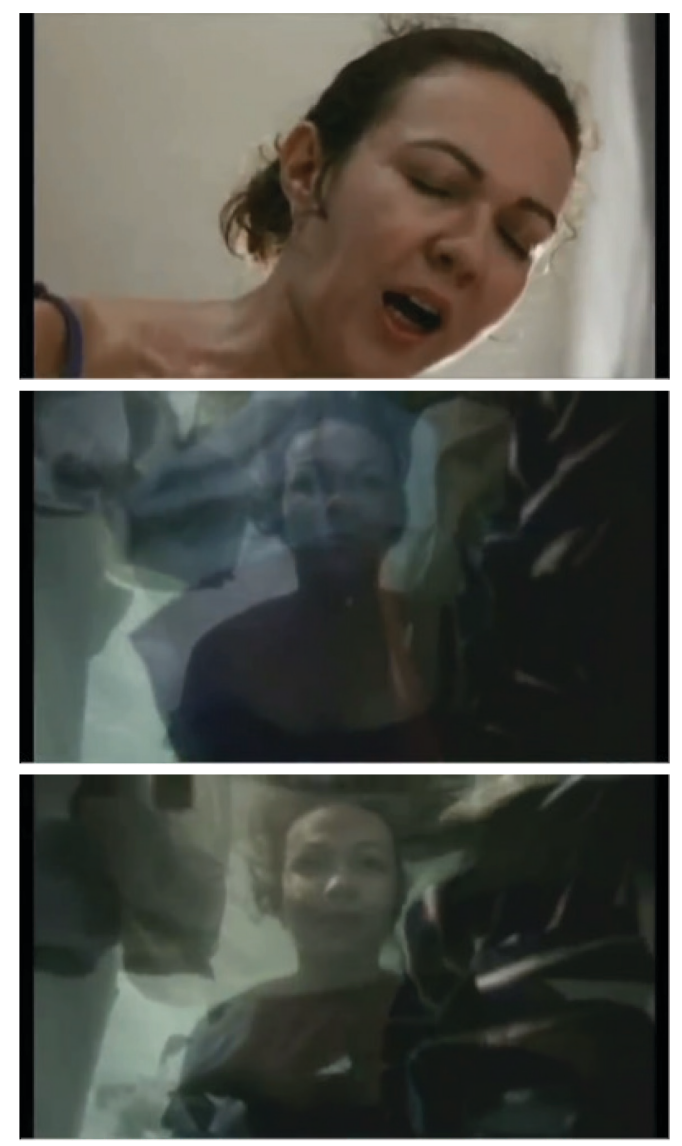

Imagem 6: Eletrodoméstica

Fonte: ELETRODOMÉSTICA (2005)

Para que serve uma máquina de lavar roupa?

\section{A IMAGEM EM EQUÍVOCO}

Os dois últimos fotogramas acima resumem, visualmente, a contradição estruturante do curta-metragem Eletrodoméstica. Sujeito e máquina em simbiose, tal como marcado pelo próprio neologismo 'eletrodoméstica'. Onde fica a separação? Na equivocidade da imagem, o corpo em gozo mergulha e se mistura às roupas.

O desejo explode em prazer e o olhar controlado pelo cronômetro em todo o curta encontra o olhar perdido por entre as grades que abre o filme na busca do que falta sempre. O olhar do espectador se depara com o olhar que sorri, extasiado, dentro da máquina de lavar roupa. O gozo é o escape possível.

O trajeto do olhar, em Eletrodoméstica, fica delineado entre a clausura das grades, na sequência das tarefas que domesticam o dia a dia. Mas o desejo insiste na busca do prazer, o desejo faz resistência no corpo, e a equivocidade dos sentidos movimenta o cotidiano em brechas que fazem o olhar vazar e o sujeito gozar.

O olhar é uma prática ideológica capaz de subversão, justamente quando faz retorno sobre o sujeito. Este é um ponto importante, que faz eco em minha retomada discursiva da afirmação de Didi Huberman (1998, p. 29): "O que vemos só vale - só vive - em nossos olhos pelo que nos olha”.

Com a compreensão de que o olhar se constitui na alteridade, trago uma interessante afirmação de Novaes (1988, p. 9): "o olhar deseja sempre mais do que é dado a ver". Nessa mesma direção, Mariani (2017, p. 43) afirma que “o desejo, através do olhar, interroga o que se vê”. Portanto, quando o olhar faz retorno sobre o sujeito, os sentidos se movimentam pelo desejo do que sempre falta(rá). 
Nesses percursos que se abrem, a história vai ancorando o sujeito com suas versões disponíveis, enquanto a resistência, no jogo entre $\mathrm{o}$ (re)conhecimento e o (des)conhecimento que constitui o processo de identificação do sujeito, busca subverter essas versões.

Eletrodoméstica coloca o desejo em cena no corpo, em imagens que convocam o olhar do espectador e o lançam em trajetos que vão delineando esse trabalho da resistência sobre o sujeito. No entrecruzar dos olhares, o espectador se vê interrogado, em seus desejos, em suas ancoragens simbólicas, num processo de captura simbólica que o afeta em sua inscrição no social. Nos diferentes trajetos do olhar, a potência da imagem demanda, na alteridade dos sentidos, o que sempre pode ser visto por entre as brechas, em meio aos rituais falhos. Um vir a ser do olhar...

\section{REFERÊNCIAS}

BOCA de lixo. Direção de Eduardo Coutinho. Rio de Janeiro: Centro de Criação de Imagem Popular, 1992 (50min.).

DIDI-HUBERMAN, G. O que vemos, o que nos olha. São Paulo: Editora 34, 1998.

DUCROT, O.; TODOROV, T. Dicionário das ciências da linguagem. Lisboa: Publicações Dom Quixote, 1982.

ELETRODOMÉSTICA. Direção de Kléber Mendonça Filho. Pernambuco: Cinemascópio Produções Cinematográficas, 2005 (22min.).

LAGAZZI, S. O recorte significante na memória. ]Apresentação no III SEAD - Seminário de Estudos em Análise do Discurso, UFRGS, Porto Alegre, 2007]. In: INDURSKY, F.; FERREIRA, M. C. L.; MITTMANN, S. (org.). O discurso na contemporaneidade. materialidades e fronteiras. São Carlos: Claraluz, 2009. p. 67-78.

LAGAZZI, S. A imagem do corpo no foco da metáfora e da metonímia. REDISCO, Vitória da Conquista, v. 2., n. 1, p. 104-110, jan./jun. 2013.

LAGAZZI, S. Metaforizações metonímicas do social. In: ORLANDI, E. (org.). Linguagem, sociedade, políticas. Pouso Alegre: UNIVÁS; Campinas: RG Editores, 2014. p. 105-112.

LAGAZZI, S. Paráfrases da imagem e cenas prototípicas: em torno da memória e do equívoco. In: FLORES, G.; GALLO, S.; LAGAZZI, S.; NECKEL, N.; PFEIFFER, C.; ZOPPI-FONTANA, M. (org.). Análise de discurso em rede: cultura e mídia. v. 1. Campinas: Pontes, 2015. p. 177-189.

LAGAZZI, S. Trajetos do sujeito na composição fílmica. In: FLORES, G.; GALLO, S.; LAGAZZI, S.; NECKEL, N.; PFEIFFER, C.; ZOPPI-FONTANA, M. (org.). Análise de discurso em rede: cultura e mídia. v. 3. Campinas: Pontes, 2017. p. 23-39.

LAGAZZI, S. A imagem como uma tecnologia política: o social sempre em questão. In: FARIA, J. P. de; SANTANA, J. C.; NOGUEIRA, L. (org.). Linguagem, arte e o político. Campinas: Pontes, 2020. p. 91-102.

MARIANI, B. (In)dizível, in(dizível), in(visível): linguística, análise de discurso, psicanálise. In: Indizivel, imperceptível e ininteligível: o sujeito contemporâneo e seus arquivos. Mariani, B.; Moreira, C. B; Dias, J. P.; Beck, M. (orgs.). Niterói: Eduff, 2017. p. 31-47.

NOVAES, A. O olhar. São Paulo: Companhia das Letras, 1988.

ORLANDI, E. Discurso e texto: formulação e circulação dos sentidos. Campinas: Pontes, 2001.

PÊCHEUX, M. O discurso: estrutura ou acontecimento? Campinas: Pontes, 1990. 
SILVEIRA, J. Sujeitos ordinários e efeito-rumor: discurso, arquivo, tecnologia. In: FLORES, G.; GALLO, S.; LAGAZZI, S.; NECKEL, N.; PFEIFFER, C.; ZOPPI-FONTANA, M. (org.). Análise de discurso em rede: cultura e mídia. v. 4. Campinas: Pontes, 2019. p. 37 58.

\section{(ㄷ) (1) $\circledast$}

Recebido em 23/02/2021. Aceito em 14/04/2021. 